\title{
Effect of Entonox on reducing the need for Pethidine and the Relevant Fetal and Maternal Complications for Painless Labor
}

\author{
Alireza Sharifian Attar ${ }^{1}$, Atefe Shirinzadeh Feizabadi ${ }^{2}$, Lida Jarahi ${ }^{3}$, Laya Shirinzadeh Feizabadi ${ }^{4}$, Shima \\ Sheybani ${ }^{5}$
}

${ }^{1}$ M.D., Associate Professor, Department of Anesthesiology, Faculty of Medicine, Mashhad University of Medical Sciences, Mashhad, Iran

${ }^{2}$ M.D., Resident of Anesthesiology, Department of Anesthesiology, Faculty of Medicine, Mashhad University of Medical Sciences, Iran

${ }^{3}$ M.D., Associate Professor of Community Medicine, Department of Community Medicine, Faculty of Medicine, Mashhad University of Medical Sciences, Mashhad, Iran

${ }^{4}$ M.D., Fellowship of Gynecologic Oncology, Faculty of Medicine, Mashhad University of Medical Sciences, Mashhad, Iran

${ }^{5}$ M.D., Fellowship of Anesthesia in Cardiac Surgery, Assistant Professor of Anesthesiology, Faculty of Medicine, Mashhad University of Medical Sciences, Mashhad, Iran

Type of article: Original

\begin{abstract}
Background: Pain relief during labour is one of the major concerns in obstetrics; severe labor pain causes fear of the next pregnancy, and interferes with the mother's family relationship.

Objective: The aim of this study was to evaluate the analgesic effects of Entonox during labor on reducing the need for pethidine (Meperidine) and fetal-maternal complications.

Methods: This double-blind randomized clinical trial was conducted on pregnant women who were candidates for vaginal delivery in Educational Hospitals of Mashhad University of Medical Sciences, Iran between January 2014 and November 2015. After entering into the inactive phase of labor, participants were randomly allocated to receive inhaled Entonox gas $(n=200)$ or inhale Oxygen $(n=200)$ as a control group. Mothers inhaled the gas at commencement of pain, and ceased as soon as the pain diminished, up to the end of the second stage of labor which was the neonate's birth. Main outcomes were pain score based on NRS (numerical rating scale), duration of delivery, required pethidine, maternal complications and satisfaction during labour. Chi-square and Independent T-test were used via SPSS for data analysis and P-value less than 0.05 was considered statistically significant.

Results: Four-hundred pregnant women with a mean age of $26.4 \pm 5.9$ years were studied. Complications such as nausea, vomiting, dizziness, and drowsiness were reported in $25 \%$ of the Entonox group and $23 \%$ in the control group $(\mathrm{p}=0.640$ ). Mean of pain severity score during labor in the Entonox and control groups was $4.5 \pm 1.2$ and $5.2 \pm 1.4$, respectively $(\mathrm{p}<0.001)$. Pethidine requirement, significantly was lower in the Entonox group $(31.6 \pm 11.8$ versus $35.7 \pm 12.4 ; \mathrm{p}<0.001)$.

Conclusion: In our study, Entonox significantly reduced pain during delivery without significant increase in maternal and neonatal complications.

Trial registration: The trial is registered at the Iranian Clinical Trial Registry (IRCT.ir) with the IRCT identification number IRCT2015102713159N6.

Funding: This research has been financially supported by Research Council of Mashhad University of Medical Sciences.

Keywords: Entonox, Analgesia, Obstetrical, Pethidine, Narcotics, Inhalation

\section{Corresponding author:}

Assistant Professor Dr. Shima Sheybani, Department of Anesthesiology, Ghaem Hospital, Mashhad University of Medical Sciences, Iran. Tel: +98.9151140314, Email: Sheybanish@mums.ac.ir

Received: January 02, 2016, Accepted: October 25, 2016, Published: December 2016

iThenticate screening: October 07, 2016, English editing: November 16, 2016, Quality control: December 03, 2016

(C) 2016 The Authors. This is an open access article under the terms of the Creative Commons Attribution-NonCommercialNoDerivs License, which permits use and distribution in any medium, provided the original work is properly cited, the use is non-commercial and no modifications or adaptations are made.
\end{abstract}




\section{Introduction}

Labour pain is one of the most painful experiences a human can endure. So much so, that fear of it has increased the rate of delivery by cesarean section, which is associated with particular problems and side effects when carried out without appropriate indication (1). The three basic principles in delivery are labor pain relief in midwifery, using an easy and safe method, and fetus homeostasis maintenance. Every mother who uses any form of painless delivery method should be precisely controlled and monitored (2). Entonox is a mixture of oxygen and nitrous oxide in equal proportions of 50-50 which its use is the highest among inhaled analgesics in the United States, and is used by $60 \%$ of women during labor (3). Due to easy use of Entonox, it can even be used at home with a mask (3-4). To gain the maximum analgesic benefits of this gas, the patient is required to be properly trained. Analgesia caused by inhaling Entonox is established within 30 seconds and the maximum effect is reached in about 2 minutes. Entonox affects the central nervous system and increases the secretion of endorphins leading to analgesia, relaxation and euphoria $(4,5)$. Since Entonox is quickly excreted within the respiratory system, it seems to have no effect on the fetus (6). Entonox can also be used in wound suturing, postoperative pain control, wound debridement and changing burns dressings. This analgesic in labor pain control leads to painless vaginal delivery (7). Use of Entonox, despite appropriate analgesic effect in various stages of delivery, has no effect on the neonate's Apgar score and postpartum hemorrhage (8). Given the high rate of cesareans in Iran and the fact that the fear of labor sometimes results in selection of cesarean section (9), it is recommended that methods in which vaginal delivery can be performed successfully without pain or complications are sought. One of the ways which helps us is to use Entonox which unfortunately is not routinely used, due to lack of knowledge about it. Entonox can reduce the pain of natural vaginal delivery, increase cases of vaginal delivery and reduce unnecessary caesarean sections and the need of pethidine. Therefore, according to the research priorities of painless delivery in our hospital, in addition to the evaluation of the effects of Entonox on labor pain intensity, the current study aimed to assess the effects of Entonox on mothers' hemodynamic, neonates' Apgar, blood oxygen saturation, umbilical cord PH after birth, and also need of pethidine, and finally the incidence of adverse effects such as nausea, vomiting, dizziness, and drowsiness.

\section{Material and Methods}

\subsection{Research design and setting}

This double-blind clinical trial study was performed on pregnant women who were candidates for vaginal delivery in three main referral teaching hospitals of Mashhad University of Medical Sciences, Mashhad, Iran between January 2014 and November 2015.

\subsection{Sampling and sample size determination}

The sample size was an estimated 210 patients for each group, considering Alfa $=0.05$, Beta $=0.2, Z_{1-a / 2}=1.96, Z_{1}$. $\beta=0.84, P_{1}=0.80, P_{2}=0.68, P=0.74$. Based on aforementioned information the sample size was measured as 400 divided in two equal groups. Final samples were selected based on simple random sampling methods (Figure 1).

\subsection{Randomization, allocation and blinding}

By using random number tables, the mothers were randomly allocated to one of the two groups: Entonox: intervention group or Oxygen: control group. The surgeons were blind to the groups of intervention and just one research assistant was aware of precipitants group. Moreover, patients and statistician were also blind to the types of interventions.

\subsection{Selection criteria}

Nulliparous women aged 18-40 years, term pregnancy (37-42 weeks), singleton, normal fetus, no medical and midwifery complications of mother (heart problems or other internal diseases), no use of other anesthesia or analgesia drugs, cephalic presentation, no restrictions for Entonox gas inhalation (respiratory diseases, pneumothorax, history of head trauma), having a dilatation of $4 \mathrm{~cm}$ at the beginning of the active phase of delivery when entering into the study, and normal fetal heart pattern were included in this study, and patients with any complication during childbirth, lack of consent to enter the project, and those who required cesarean delivery were excluded from the study.

\subsection{Data collection}

A check list was used for data collection. At the beginning of admittance to the hospital, after the standard monitoring of mothers' vital signs including heart rate, pulse oximetry, blood pressure and respiratory rate, fetal heart rate was also measured and recorded in checklist as well as maternal primary vital signs. 


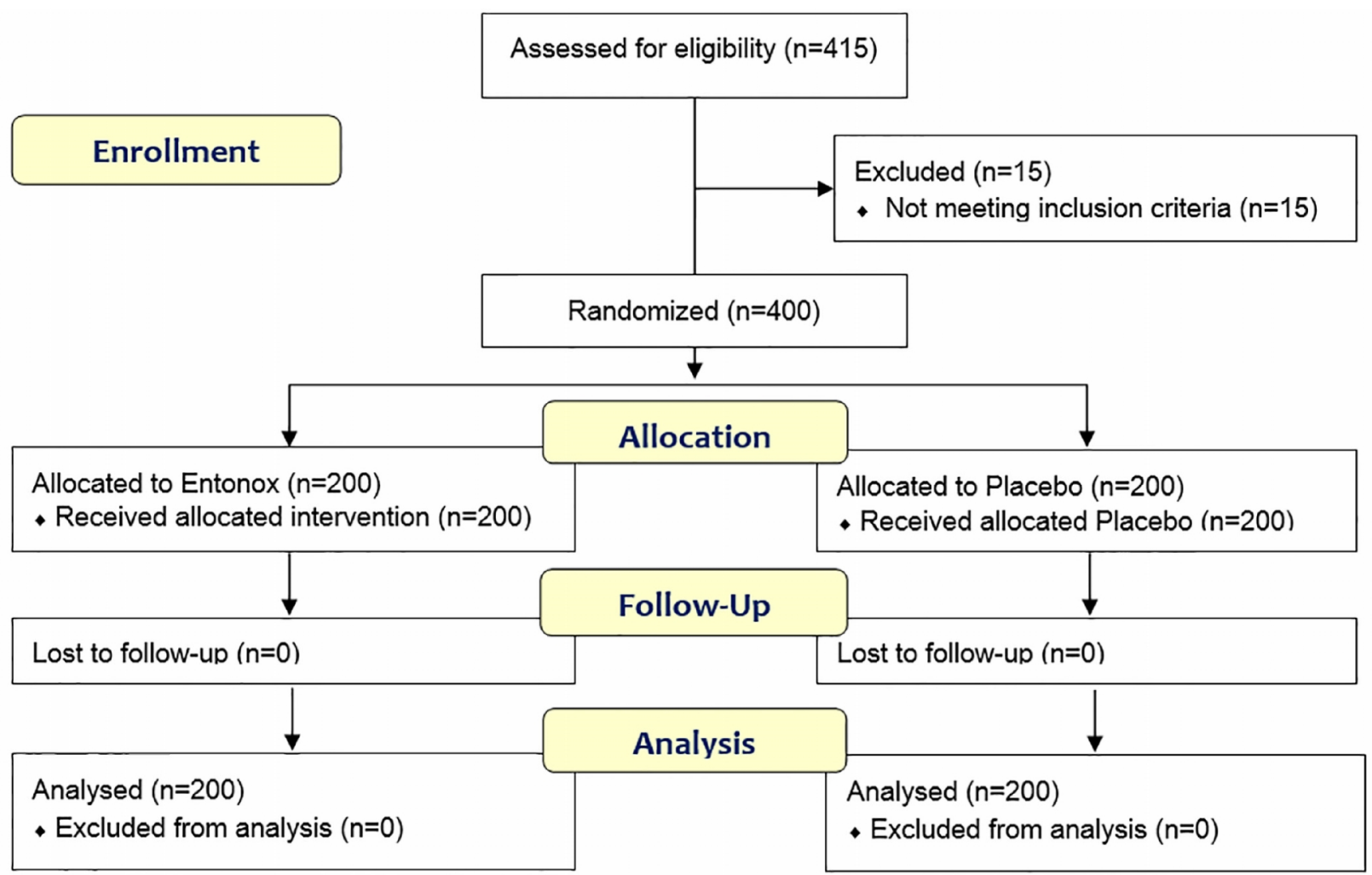

Figure 1. Follow-up diagram of patients (According to consort statement)

\subsection{Interventions}

The Entonox group received inhaled gas containing 50\% oxygen and 50\% nitric oxide and the Oxygen group received 4-6 lit/min oxygen only. After entering the active phase of labor (cervical dilatation of $4 \mathrm{~cm}$ ), both groups were given the masks of which the intervention group inhaled Entonox and the control group inhaled oxygen. Mothers began inhaling through the masks at the beginning of pain, and as soon as the pain receded, the gas inhalation ended. Mothers would frequently receive gas up to the end of the second stage of lab or which was neonate's birth. The patients were frequently controlled by an anesthesia assistant. If (NSR $>4$ ), $0.5 \mathrm{mg} / \mathrm{kg}$, intravenous pethidine was administered for patients of the two groups in severe pain, and was recorded.

\subsection{Outcomes}

Pain intensity and maternal hemodynamics status (while receiving gas, and recorded every fifteen minutes), fetal heart rate, duration of the active phase and second stage of labor, 1 and 5 minutes Apgar score, infant's saturation (by pulse oximetry), and infant's cord $\mathrm{pH}$ (by arterial blood gas analysis after birth) was recorded and compared between the two groups. Also, the need for additional pethidine (in case of NSR $>4$ ) in both groups during childbirth was recorded. In addition, any adverse effects such as nausea, vomiting, dizziness, or drowsiness was mentioned in our check list and compared between the two groups.

2.7.1. Pain assessment

Pain assessment scale was numeric scale rating (NRS). Pain intensity was measured using the numbers of 0 to 10 that 0 represents complete analgesia and 10 represents the maximum pain that can be imagined.

2.7.2. Satisfaction

In our study, satisfaction level was studied in two main categories; complete satisfaction and relative satisfaction. Patients were assumed to be completely satisfied if there was no nausea, vomiting, dizziness drowsiness, or intolerance during and after interventions. On the other hand, they were assumed relatively satisfied, if there were any degree of the mentioned parameters.

\subsection{Research ethics}

After approval by the ethics committee of Mashhad University of Medical Sciences (Code: 966778) and registration in IRCT system (IRCT2015102713159N6) and obtaining the written consent of mothers, this study began in maternities of Mashhad University Educational Hospitals. In case of appearance of any gas inhalation 
http://www.ephysician.ir

related complications, interventions were stopped and were recorded in the checklist, and then when the complication disappeared, the mask was again used, if it was needed.

\subsection{Statistical analyses}

Statistical analysis was performed using SPSS software version 16. For nominal variables, chi-square test was used and if needed, Fisher's exact test was performed. Kolmogorov-Simonov was used to determine normality of distribution. For comparative dependent data, paired T-test (parametric) and if non-parametric, Wilcoxon test were used. For comparing the independent data, independent-samples t-test (parametric) was used and if nonparametric, Mann-Whitney $U$ test was used. In all measurements p-value less than 0.05 was considered statistically significant.

\section{Results}

In this study, 400 women with mean age of $26.4 \pm 5.9$ years, 200 in control (Oxygen) and 200 in intervention group (Entonox) were studied. The frequency of age groups $<18$ years, 18 to 30 years, and $>30$ years was $3 \%$, $72.2 \%$ and $24.8 \%$, respectively. The mean gestational age was $38.7 \pm 2.6$ weeks. The mean of pain severity in total of patients when referring was $7.7 \pm 1.7$. Two groups were homogenous according to maternal age, mother's pain severity and vital signs at the time of study entrance (Table 1). Results revealed that, patients in the Entonox group experienced less pain $(\mathrm{p}=<0.001)$ and they also had less duration of delivery in the first $(\mathrm{p}=<0.001)$ and second $(\mathrm{p}=0.004)$ stage (Table 2$)$. In addition, the required dosage of pethidine needed during labor was significantly lower in the Entonox group $(\mathrm{p}=<0.001)$ (Table 2). However, there was no significant difference between the two groups in terms of Neonate's Apgar scores and artery oxygen saturation (Table 2). The incidence of complications of nausea, vomiting, dizziness and drowsiness were observed in $24.5 \%$ of the Entonox group patients and $23 \%$ of Oxygen group patients, but the difference was not statistically significant $(\mathrm{p}=0.640)$ (Table 3). In Table 3, the frequency of complications and maternal satisfaction of analgesia methods were compared.

Table 1. Comparison of baseline maternal characteristics between two groups of Entonox and Oxygen intervention

\begin{tabular}{|l|l|l|l|}
\hline Variables, mean \pm SD & $\begin{array}{l}\text { Oxygen } \\
(\mathrm{n}=200)\end{array}$ & $\begin{array}{l}\text { Entonox } \\
(\mathrm{n}=200)\end{array}$ & p-value \\
\hline Maternal age (year) & $26.9 \pm 5.7$ & $26 \pm 6$ & 0.138 \\
\hline Pain severity when entering to the study (score) & $7.74 \pm 1.7$ & $7.76 \pm 1.7$ & 0.089 \\
\hline Mother's systolic blood pressure $(\mathrm{mmHg})$ & $98.8 \pm 5.8$ & $99.5 \pm 4.8$ & 0.261 \\
\hline Mother's diastolic blood pressure $(\mathrm{mmHg})$ & $62.9 \pm 9$ & $68.4 \pm 3.8$ & 0.248 \\
\hline Maternal pulse rate (min) & $86.3 \pm 8.1$ & $86.9 \pm 8$ & 0.663 \\
\hline Maternal respiratory rate (min) & $13.9 \pm 3.2$ & $14 \pm 1.1$ & 0.678 \\
\hline Maternal artery oxygen saturation $(\%)$ & $97.5 \pm 1.4$ & $97.9 \pm 0.6$ & 0.137 \\
\hline
\end{tabular}

Table 2. Comparison of maternal and neonatal outcomes between two groups of Entonox and Oxygen intervention

\begin{tabular}{|l|l|l|l|}
\hline Variables, mean \pm SD & Oxygen $(\mathrm{n}=200)$ & Entonox $(\mathrm{n}=200)$ & $\mathrm{p}$-value \\
\hline Pain severity during labor (score) & $5.2 \pm 1.4$ & $4.5 \pm 1.2$ & $<0.001$ \\
\hline Duration of delivery first stage (min) & $150.5 \pm 69.2$ & $103.4 \pm 56.6$ & $<0.001$ \\
\hline Duration of delivery second stage (min) & $25 \pm 14.1$ & $21.9 \pm 14$ & 0.004 \\
\hline Needed pethidine during labor, mg/dl & $35.7 \pm 12.4$ & $31.6 \pm 11.8$ & $<0.001$ \\
\hline Neonate's first Apgar score & $8.7 \pm 0.6$ & $8.7 \pm 0.7$ & 0.507 \\
\hline Neonate's fifth Apgar score & $9.7 \pm 0.5$ & $9.6 \pm 0.7$ & 0.343 \\
\hline Neonate's cord Apgar score & $7.32 \pm 0.77$ & $7.33 \pm 0.076$ & 0.116 \\
\hline Neonatal artery oxygen saturation $(\%)$ & $96.5 \pm 2.9$ & $96.4 \pm 2$ & 0.133 \\
\hline
\end{tabular}

Table 3. Comparison of the frequency of complications and maternal satisfaction of analgesia method 


\begin{tabular}{|l|l|l|l|l|}
\hline Variables, $\mathrm{n}(\%)$ & Entonox $(\mathrm{n}=200)$ & Oxygen $(\mathrm{n}=200)$ & $\mathrm{p}$-value \\
\hline \multirow{2}{*}{ Nausea } & Negative & $192(96)$ & $183(91.5)$ & 0.097 \\
\cline { 2 - 4 } & Positive & $8(4)$ & $17(8.5)$ & \\
\hline \multirow{2}{*}{ Vomiting } & Negative & $194(97)$ & $195(97.5)$ & \multirow{2}{*}{0.999} \\
\cline { 2 - 4 } & Positive & $6(3)$ & $5(2.5)$ & \\
\hline \multirow{2}{*}{ Dizziness } & Negative & $182(91)$ & $181(90.5)$ & 0.999 \\
\cline { 2 - 4 } & Positive & $18(9)$ & $19(9.5)$ & \\
\hline \multirow{2}{*}{ Drowsiness } & Negative & $187(93.5)$ & $189(94.5)$ & \multirow{2}{*}{0.674} \\
\cline { 2 - 4 } & Positive & $13(6.5)$ & $11(5.5)$ & \\
\hline \multirow{2}{*}{ Satisfaction } & Complete & $134(67)$ & $155(77.5)$ & 0.019 \\
\cline { 2 - 4 } & Relative & $66(33)$ & $45(22.5)$ & \\
\hline
\end{tabular}

\section{Discussion}

Pain relief is one of the main parts of midwifery, as one of the benefits of labor at the hospital is providing more technical pain relief. Severe labor pain can cause long-term emotional disturbance for a mother, and affects her mental health and has a negative impression on maternal-neonatal relationships in the first critical days after delivery. Moreover it might interfere with family relationships by causing fear of next pregnancy (10). Labor pain also reduces oxygenation of the fetus and subsequently leads to abnormal fetal heart rate patterns and decreased Apgar score, and this increases the need for obstetrical interventions and its relevant complications. Fear of labor pain is one of the main reasons of high demand for cesarean section (11). Due to the fact that delivery is a physiological process and promotion of natural vaginal delivery is considered as one of the principal policies of the health care systems, this important goal can be achieved by reducing labor pain. To reduce labor pain, we should resort to safe and secure methods for mother and fetus which, while are effective, do not cause interference with the labor process, maternal alertness or straining reflex and the mother's physiological functions (12). One of these methods is inhaled analgesia using Entonox gas (a mixture of 50\% oxygen and 50\% N2O). The benefits of Entonox are that they are fast acting, give rapid clearance from the body, there is no need for sophisticated and expensive devices, no need for highly-skilled personnel, and finally mothers have greater tolerance (13-15). For nearly fifty years, Entonox has been approved for pain relief, and is used especially in England. Most studies in Europe and the United States have compared Entonox as a standard method with other relieving methods or medicines, rather than evaluate its effects on labor pain (16-18). In the present study, complications were observed in $24.5 \%$ of patients in the Entonox group and $23 \%$ of patients in the oxygen group, but the difference was not statistically significant $(\mathrm{P}=0.640)$. The most common side effects included nausea, vomiting, dizziness, and drowsiness that often make Entonox intolerable for parturient (16). In a review article, Entonox compared with other analgesia methods caused more nausea, vomiting, dizziness, and drowsiness (17). In the study of Rezaeipour, some possible side effects caused by inhaling Entonox, such as drowsiness and dry mouth were more commonly observed in the intervention group than the control group $(\mathrm{P}<0.001)$, but no statistically significant differences were observed in other complications (18). In our study, dizziness and drowsiness were slightly more common in patients of the Entonox group, but the difference was not statistically significant $(\mathrm{P}=0.744)$, and the most likely cause of these complications in the oxygen group was higher need to use pethidine. A study in 2011 showed that Entonox is safe for mothers and neonates, and people working in the environment if it is used with oxygen at a proportion of 50:50 (19). In the study of Pazande, Entonox had no negative effects on the mother and fetus (20). In our study, the hemodynamic changes in mother and infant during labor, were not significantly different between the two groups, which confirmed the safety of Entonox for mother and neonate. In the study of Zare, the mean length of first stage of delivery was shorter in the Entonox group than the control group, but the mean length of the second stage of delivery showed no significant difference between case and control groups (21). The study of Parashi showed that nitrous oxide reduces labor duration (22). In our study, the mean duration of the first and second stage was significantly lower in the Entonox group than the oxygen group. It seems that inhalation of Entonox to reduce labor pain, also decreases the labor duration. It is known that pain increases production of catecholamines and decreases blood supply to the uterus and uterine contractions. The subsequent weakness and ineffectiveness of these contractions result in inappropriate delivery progress. In the study of Pazande, the mean of pain intensity was significantly lower in the Entonox group than other methods (23). The study of Parashi showed that nitrous oxide reduces labor pain (24). In the study of Agah, pain severity was not significantly different in the groups of continuous and discontinuous use of Entonox gas (22). In our study also, the mean pain intensity during labor was $4.5 \pm 1.2$ in the Entonox group and $5.2 \pm 1.4$ in the oxygen group, and this difference was statistically significant. In our study, Entonox was administered as 
discontinuous for the patients. Entonox gas has no effect on uterine contractions and does not cause malignant hyperthermia. Its side effects included nausea, vomiting, dizziness, and low reward. In terms of blood oxygen saturation for mothers and infants during delivery, the results of present study showed that $\mathrm{SpO} 2$ was not less than $90 \%$ in any of the methods, and that is similar to the study of Masoudi (25). In our study, maternal hemodynamic findings were not significantly different between Entonox and oxygen groups. But in a study in Lorestan, hemodynamic findings were lower in the Entonox group than other groups (25). One of the complications of acute/severe pain caused by response of sympathetic nervous system, is increased pulse rate and blood pressure; the cause of difference between our study and other studies may be due to differences in the consumption of pethidine, because the oxygen group received pethidine during pain. In a study in Tehran, Iran, no statistically significant difference was observed between the two groups in first and fifth minute Apgar score (22). In our study, the mean first and fifth minute Apgar scores in the Entonox group were not statistically significant. Therefore, it seems that Entonox decreases maternal pain and severe anxiety and consequently reduces the incidence of abnormal fetal heart rate and leads to an improved Apgar score. In the study of Jafari, the use of Entonox increased maternal satisfaction (26). In our study, none of the patients were dissatisfied from the used analgesia methods. Full satisfaction was observed in $53.6 \%$ of the Entonox group and $46.4 \%$ of the oxygen group, and relative satisfaction in $40.5 \%$ of the Entonox group and $59.5 \%$ of the oxygen group was observed, and this difference was statistically significant. According to the study findings, it seems that the use of Entonox is an effective and safe method for labor pain relief which is associated with increased maternal satisfaction, therefore, delivery satisfaction has a direct relationship with pain relief and lack of severe side effects of Entonox. Several studies have indicated that $80 \%$ of patients tend to reuse Entonox in the next pregnancies (27-28). In order to reduce the rate of caesarean sections and encourage parturient women to vaginal delivery, it is recommended that the benefits of Entonox be provided in training sessions during pregnancy, for mothers or in the form of print material in doctors' offices and clinics; and this method might be an important step in improving the health of mothers and children. One of the minor limitations of this study was a short duration of study follow-up. It would be more advantageous if a follow-up of our patients could be carried out for at least one week after their discharge.

\section{Conclusions}

In our study, Entonox significantly improved labor pain during delivery without significantly increasing maternal complications. The three main principles of pain relief in obstetrics which are simplicity, safety and fetus homeostasis maintaining are considered. Since the use of Entonox, especially in intermittent form, reduces labor pain without causing complications for the mother, and also is associated with more maternal satisfaction, this gas can be used during labor in order to reduce the number of cesarean deliveries occurring due to labor pain and as a result, the complications of surgery and anesthesia and its high costs can be decreased.

\section{Acknowledgments:}

The authors appreciate the research chancellor of Mashhad University of Medical Sciences which supported this study financially. This article is obtained from Anesthesiology Specialty student thesis by Dr. Atefeh Shirinzadeh Feizabadi (approval number 966778).

\section{Trial registration:}

The trial is registered at the Iranian Clinical Trial Registry (IRCT.ir) with the IRCT identification number IRCT2015102713159N6.

\section{Funding:}

This research has been financially supported by Research Council of Mashhad University of Medical Sciences.

\section{Conflict of Interest:}

There is no conflict of interest to be declared.

\section{Authors' contributions:}

All authors contributed to this project and article equally. All authors read and approved the final manuscript.

\section{References:}


1) Sadat Z. Reasons for elective cesarean section in Iranian women. Nurs Midwifery Stud. 2014; 3(3): e22502. doi: 10.17795/nmsjournal22502. PMID: 25699287, PMCID: 4332999.

2) Sedigh Mobarakabadi S, Mirzaei Najmabadi K, Ghazi Tabatabaie M. Ambivalence towards childbirth in a medicalized context: a qualitative inquiry among Iranian mothers. Iran Red Crescent Med J. 2015; 17(3): e24262. doi: 10.5812/ircmj.24262. PMID: 26019905, PMCID: PMC4441778.

3) Valiani M, Haghighatdana Z, Ehsanpour S. Comparison of childbirth training workshop effects on knowledge, attitude, and delivery method between mothers and couples groups referring to Isfahan health centers in Iran. Iran J Nurs Midwifery Res. 2014; 19(6): 653-8. PMID: 25558265, PMCID: 4280732.

4) Khadem N, Zirak N, Soltani G, Sahebdelfar N, Sepehri Shamloo A, Ebrahimzadeh S. Comparison of Epidural versus Entonox for Labor Analgesia in Nulliparous Women. Journal of Surgery and Trauma. 2013; 1(1): 1-5.

5) Najafi TF, Bahri N, Ebrahimipour H, Najar AV, Taleghani YM. Risk Assessment of Using Entonox for the Relief of Labor Pain: A Healthcare Failure Modes and Effects Analysis Approach. Electronic physician. 2016; 8(3): 2150-9. doi: 10.19082/2150. PMID: 27123224 , PMCID: PMC4844482.

6) Crawford C. New guideline covers labor, vaginal birth after cesarean. Annals of family medicine. 2015; 13(2): 186-7. doi: 10.1370/afm.1571. PMID: 25755044, PMCID: 4369601.

7) Metz TD, Allshouse AA, Faucett AM, Grobman WA. Validation of a vaginal birth after cesarean delivery prediction model in women with two prior cesarean deliveries. Obstet Gynecol. 2015; 125(4): 948-52. doi: 10.1097/AOG.0000000000000744. PMID: 25751218, PMCID: 4372471.

8) Villar J, Valladares E, Wojdyla D, Zavaleta N, Carroli G, Velazco A, et al. Caesarean delivery rates and pregnancy outcomes: the 2005 WHO global survey on maternal and perinatal health in Latin America. Lancet. 2006; 367(9525): 1819-29. doi: 10.1016/S0140-6736(06)68704-7. PMID: 16753484.

9) Monari F, Di Mario S, Facchinetti F, Basevi V. Obstetricians' and midwives' attitudes toward cesarean section. Birth. 2008; 35(2): 129-35. doi: 10.1111/j.1523-536X.2008.00226.x. PMID: 18507584.

10) Lyerly $\mathrm{AD}$, Little MO. Toward an ethically responsible approach to vaginal birth after cesarean. Semin Perinatol. 2010; 34(5): 337-44. doi: 10.1053/j.semperi.2010.05.007. PMID: 20869550, PMCID: 2946940.

11) Grobman WA, Lai Y, Landon MB, Spong CY, Leveno KJ, Rouse DJ, et al. Can a prediction model for vaginal birth after cesarean also predict the probability of morbidity related to a trial of labor? Am J Obstet Gynecol. 2009; 200(1): 56.e1-6. doi: 10.1016/j.ajog.2008.06.039. PMID: 18822401, PMCID: PMC2743567.

12) Grobman WA, Lai Y, Landon MB, Spong CY, Leveno KJ, Rouse DJ, et al. Prediction of uterine rupture associated with attempted vaginal birth after cesarean delivery. Am J Obstet Gynecol. 2008; 199(1): 30.e1 5. doi: 10.1016/j.ajog.2008.03.039. PMID: 18439555, PMCID: PMC2532505.

13) Clark SM, Carver AR, Hankins GD. Vaginal birth after cesarean and trial of labor after cesarean: what should we be recommending relative to maternal risk:benefit? Womens Health (Lond). 2012; 8(4): $371-83$. doi: 10.2217/whe.12.28. PMID: 22757729.

14) Barger MK, Weiss J, Nannini A, Werler M, Heeren T, Stubblefield PG. Risk factors for uterine rupture among women who attempt a vaginal birth after a previous cesarean: a case-control study. J Reprod Med. 2011; 56(7-8): 313-20. PMID: 21838161.

15) Oboro V, Adewunmi A, Ande A, Olagbuji B, Ezeanochie M, Oyeniran A. Morbidity associated with failed vaginal birth after cesarean section. Acta Obstet Gynecol Scand. 2010; 89(9): 1229-32. doi: 10.3109/00016349.2010.499448. PMID: 20804350.

16) Likis FE, Andrews JC, Collins MR, Lewis RM, Seroogy JJ, Starr SA, et al. Nitrous oxide for the management of labor pain: a systematic review. Anesth Analg. 2014; 118(1): 153-67. doi: 10.1213/ANE.0b013e3182a7f73c. PMID: 24356165.

17) Klomp T, van Poppel M, Jones L, Lazet J, Di Nisio M, Lagro-Janssen AL. Inhaled analgesia for pain management in labour. Cochrane Database Syst Rev. 2012; (9): CD009351. doi: 10.1002/14651858.CD009351.pub2. PMID: 22972140.

18) Rezaeipour A, Idenloo F, Khakbazan Z, Kazemnejad K. The effects of Entonox on implication of painless labor and delivery satisfaction rate among pregnant women. Hayat. 2008; 13(4): 45-58.

19) Rooks JP. Safety and risks of nitrous oxide labor analgesia: a review. J Midwifery Womens Health. 2011; 56(6): 557-65. doi: 10.1111/j.1542-2011.2011.00122.x. PMID: 22060215.

20) Zare Tazarjani F, Sekhavat L, Karimzadeh Mibodi M. The Effect of Continuous Entonox Inhalation on the Length of Labor in Duration of Active Phase of Labor. Journal of Babol University Of Medical Sciences. 2010; 11(6): 21-5. 
21) Talebi H, Nourozi A, Jamilian M, Baharfar N, Eghtesadi-Araghi P. Entonox for labor pain: a randomized placebo controlled trial. Pak J Biol Sci. 2009; 12(17): 1217-21. doi.org/10.3923/pjbs.2009.1217.1221. PMID: 19943458.

22) Agah J, Baghani R, Yaser Y. Comparison of Continuous and Intermittent Inhalation Methods of Entonox on Labor Pain: a Randomized Clinical Trial. Journal of Mazandaran University of Medical Sciences. 2014; 23(1): 87-93.

23) Furmanik J. Labour epidural analgesia in Poland in 2009 - a survey. Anaesthesiol Intensive Ther. 2013; 45(3): 149-52. doi: 10.5603/AIT.2013.0031. PMID: 24092511.

24) Parashi S, Kashanian M, Rabbani O. Comparison between entonox and oxygen on lowering labor pain and the progress of labor. Razi Journal of Medical Sciences. 2013; 20(112): 45-52.

25) Masoudi M, Akbari S. The comparison of Entonox and warm water effect on labor pain. Yafte. 2011; 12(2): $0-0$.

26) Mohammad Jafari R, Barati M, Torabzadeh Bafghi V, Torabzadeh Bafghi A. The effect of entonox gas inhalation on the duration of active phase of labor and outcome of delivery. Jundishapur Scientific Medical Journal. 2013; 12(1(82)): 13-9.

27) Varposhti MR, Ahmadi N, Masoodifar M, Shahshahan Z, Tabatabaie MH. Comparison of remifentanil: Entonox with Entonox alone in labor analgesia. Adv Biomed Res. 2013; 2: 87. doi: 10.4103/22779175.122511. PMID: 24524033, PMCID: PMC3908727.

28) Esfandiari M, Karimi S. Effectiveness of Entonox on Severity of Labor Pain in Women Referred to Maternity Ward of Imam Reza hospital Kermanshah, 2007. Journal of Ilam University of Medical Sciences. 2009; 17(1): 25-30. 